\title{
Immunizations in Patients with Inflammatory Bowel Disease
}

\author{
Ying Lu, MD, Denise Jacobson, PhD, MPH, and Athos Bousvaros, MD, MPH \\ Inflammatory Bowel Disease Center, Division of Gastroenterology, Children's Hospital Boston, \\ Department of Pediatrics, Harvard Medical School, Boston, Massachusetts, USA 02115
}

\section{Introduction}

Evidence is mounting that patients with Crohn's disease (CD) and ulcerative colitis (UC) have subtle alterations in immunity, and that the medications used to treat these conditions may increase the risk of infection. Genetic mutations that are associated with changes in innate immunity (including NOD2 and IL23R) have been found in inflammatory bowel disease (IBD) patients. [1-4] Functional assays also suggest that adaptive immunity is altered in $\mathrm{CD}$ and UC. In CD, there is evidence of an exaggerated Th1 inflammatory response, including increased production of interferon- $\gamma$ by intestinal CD4+ T-cells, and increased IL-12 and IL-18 by mucosal macrophages. In contrast, UC is generally characterized by an excessive Th $2 \mathrm{~T}$ helper response. T-cells from UC patients produce a larger amount of IL-13 and IL-5, have a slower cell cycle, and are more prone to undergo apoptosis than control cells. [5]

In order to control intestinal inflammation, physicians often treat IBD patients with immunosuppressive therapies [corticosteroids, immunomodulators, calcineurin inhibitors, and tumor necrosis factor (TNF) inhibitors]. [6] Immunosuppressive medications can be further categorized by their mechanism of action. Corticosteroids operate by various mechanisms, such as altering gene transcription in various cells involved in immune response to ultimately reduce inflammation. Azathioprine, 6-mercaptopurine, and methotrexate all inhibit DNA synthesis, resulting in decreased lymphocyte number and function. Cyclosporine and tacrolimus are calcineurin inhibitors that prevent transcription of IL-2 to hinder T-cell activation. Infliximab and adalimumab are monoclonal antibodies used to bind TNF alpha, and can also induce monocyte apoptosis. [6] Thus, the degree of immunosuppression in IBD patients may vary by type of therapy they receive.

IBD patients may be at risk for infections due to underlying disease, malnutrition, surgery, or immunosuppressive therapy. [7, 8] Table 1 lists opportunistic infections that have been observed in IBD patients, as well as preventive mechanisms and screening tests for these infections. Some studies have looked at infection rates in IBD patients overall and others have focused on patients receiving immunosuppressive medications. In one study, there was a higher prevalence of Clostridium difficile among IBD patients compared to gastrointestinal patients without IBD and general medical patients. [9] Another study found that $15.8 \%$ of

Address Correspondence to: Athos Bousvaros, MD, MPH, GI Division - Inflammatory Bowel Disease Center, Hunnewell Ground, Children's Hospital Boston, 300 Longwood Avenue, Boston, MA 02115, athos.bousvaros@childrens.harvard.edu. 
IBD patients were infected with cytomegalovirus (CMV). [10] In addition, data have shown that women with IBD are at a higher risk for abnormal Pap smears (18-42.5\%) compared to healthy age-matched controls $(5-7 \%)$. [11, 12] In a number of case studies or case series, various opportunistic infections were observed in IBD patients on immunosuppressive therapies, including corticosteroids, 6-mercaptopurine, azathioprine, cyclosporine, or infliximab. These infections include cytomegalovirus (CMV colitis, pneumonitis, myocarditis, mononucleosis), [13] Epstein-Barr virus (resulting in death from multiorgan failure), [14] herpes simplex virus (leading to pneumonia and acute respiratory distress syndrome), [15] varicella (varicella pneumonia, shingles), [16, 17] tuberculosis, [18] histoplasmosis, [19, 20] and Pneumocystis jiroveci (carinii) pneumonia. [21, 22]

Because of the potential susceptibility of IBD patients to infection, immunization may play a critical role in preventing illness. However, there is a paucity of data that evaluates the immune response to routine vaccinations in IBD patients. This article will review the currently available recommendations, as well as the few formal vaccine studies that evaluate the immune response to immunizations in IBD patients receiving immunosuppressive therapy. Based on the current data, further recommendations for research will be proposed.

\section{Assessing the efficacy of immunizations}

The immune system recognizes and responds to antigens through the production of antibodies and/or activated immune cells. Vaccines contain live or killed microorganisms or synthesized particles. The body mounts an immune response to the vaccine antigens that results in memory cells that are prepared to respond to future exposure to wild type organisms. Antibody levels to vaccine antigens are measured to determine the degree of immunologic response to the vaccine. Investigators studying vaccine efficacy typically draw antibody levels before immunization and at a fixed time point after immunization (e.g., 4 weeks after the final immunization in a series). By comparing the antibody titer before and after immunization, a vaccine's immunogenicity can be determined.

Various terms are utilized in the immunization literature to describe vaccine immunogenicity. Seroconversion to vaccination is defined as the development of antibodies (seropositive) after immunization in a person without a detectable titer before vaccination (seronegative). A patient who seroconverts must develop a minimum antibody titer to be protected against wild type infection. Thus, when the antibody titer to the vaccine antigens reaches or exceeds this threshold, a patient is seroprotected. The average titer in a group of patients that has been immunized is called the geometric mean titer (GMT).

\section{Immunization studies in adults and children with chronic illnesses other than inflammatory bowel disease.}

\section{Children with non-IBD chronic illness may have decreased rates of immunization and decreased immune response}

Immunizations are especially important in patients with chronic illnesses or in immunocompromised patients because the hosts are more susceptible to infection. However, data have shown that such patients tend to be under-immunized or have inadequate levels of 
seroprotection after immunization. Zignol et al [23] evaluated titers to various childhood vaccines (hepatitis B, measles, mumps, rubella, tetanus, polio) in children with malignancies before and after they received chemotherapy. The percentage that lost seroprotective antibodies to the above vaccines ranged from $8 \%$ for polio to $52 \%$ for hepatitis B. Fortunately, subjects in this group who were given a booster vaccination had an overall response rate of 93\%. [23] Another study found that only $4 \%$ of pediatric renal transplant patients received all necessary vaccinations before and after transplantation. [24]

\section{Prior studies on immune response to vaccines in immunocompromised children}

Immunocompromised children have varying degrees of immune response to vaccination. The immune response to vaccination was adequate in two studies of HIV-infected infants. In a randomized trial conducted by the Pediatric AIDS Clinical Trials Group, infants with HIV were immunized with doses of heptavalent pneumococcal conjugate vaccine in a 2:1 placebo-controlled randomized trial. The baseline median $\mathrm{CD} 4^{+}$cell count between the vaccine and placebo groups was similar (2457 cells $/ \mathrm{mm}^{3}$ in the vaccine arm, $1870 \mathrm{cells} / \mathrm{mm}^{3}$ in the placebo arm, $\mathrm{p}=0.44$ ). The HIV positive infants produced a good immune response after receiving the primary series and booster vaccines for the heptavalent vaccine. However, patients with symptomatic HIV had a slightly higher incidence of adverse events (including extremity induration and fever). [25] A similar study of Haemophilus influenzae type b conjugate vaccine once again demonstrated a similar antibody response (titer $>0.15 \mathrm{mg} / \mathrm{L}$ ) in HIV-infected infants compared to HIV-exposed but uninfected infants after receiving the primary series and booster doses. The mean $\mathrm{CD} 4^{+}$cell count differed between these two

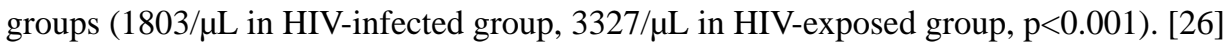

In contrast to children with HIV infection, children who are treated with chemotherapeutic agents for cancer may have a suboptimal serologic response to vaccines. One study vaccinated pediatric oncology patients with two doses of influenza vaccine and found that unprimed subjects had a 40-65\% seroconversion rate [ $\geq 4$ increase in hemagglutination inhibition (HAI)] and 38-72\% seroprotection rate (HAI 240 ) to the three influenza strains in the vaccine. However, subjects who were receiving chemotherapy exhibited a poorer immune response to influenza A strains compared to subjects who completed chemotherapy at least one month prior to vaccination. This latter group of children who completed chemotherapy produced an immune response comparable to healthy children. [27]

Booster immunizations have been shown to increase serologic response to childhood vaccinations in renal disease. Vaccine studies in children with chronic renal disease demonstrate that immunogenicity improves with repeated vaccine doses. One study showed that subjects who were immunized with influenza vaccine over two consecutive influenza seasons had a post-vaccination seroprotection rate of 50-61.5\% in the first year and $100 \%$ in the second year. [28] Two other studies on hepatitis B vaccination in this type of patient population suggested that the percentage of responders increases if booster doses are administered to subjects who are not immune after the primary series. [29, 30]

Studies on response to live vaccines administered to immunosuppressed children suggest that these patients may produce a good immune response. One study vaccinated children before liver transplantation, and revaccinated them at least one year after transplantation if 
their antibody titers had waned. The conditions for revaccination included: (1) no rejection in the most recent 6 months, (2) stable condition of the patient, (3) normal liver function, (4) tacrolimus trough $<5 \mathrm{ng} / \mathrm{mL}$ and cyclosporine trough $<50 \mathrm{ng} / \mathrm{mL}$, and (5) at least 6 months since the last use of corticosteroids. The seroconversion rates against measles, mumps, rubella and varicella were $82-100 \%$ for subjects who were vaccinated prior to transplant. The seroconversion rates were $71-100 \%$ for patients who were revaccinated after transplant. Twenty-one percent of patients acquired natural infection ( 3 measles, 7 mumps, and 5 varicella) when their antibody titers were low, within 10-68 months post-vaccination (9-65 months post-transplantation). No serious illnesses or side effects occurred. [31] One small study administered varicella vaccine to liver and intestine transplant recipients without a history of chickenpox. The patients were vaccinated at a median of 393 days (range 257-2045 days) post-transplantation. All patients were on immunosuppressive therapy (tacrolimus, sirolimus, cyclosporine, corticosteroids) at the time. Approximately $85 \%$ of subjects produced an immune response. Twenty-five percent (4/16) of subjects developed a vesicular rash within 1-24 days post-vaccination. Three of these four patients were treated with oral acyclovir, and lesions healed in all four children within 1-7 days. Fever occurred in one of these subjects with a rash and in another 3 subjects without a rash. The fever started 1-27 days post-vaccination and lasted 2-14 days. [32] However, another small study showed that patients on dialysis who were vaccinated with measles-mumps-rubella vaccine had a lower serologic response to all three (30\%) compared to healthy children $(91 \%)$. No clinical symptoms of measles, mumps, or rubella infection were noted after vaccination. [33]

\section{Prior studies on immune response to vaccines in immunocompromised adult patients}

Vaccine studies in patients with chronic illness suggest there are varying degrees of serologic response to vaccination in adults. Several studies have shown that adult patients with rheumatoid arthritis (RA) have similar antibody titer levels to influenza vaccine compared to controls. [34, 35] However, Fomin et al [36] showed that the post-vaccination geometric mean titer (GMT) and response rate (defined as a $\geq 4$-fold increase in titers) in RA patients receiving immunosuppressive therapy were lower for one of three vaccine strains compared to healthy controls.

Patients with systemic lupus erythematosus (SLE) have a decreased response to pneumococcus, [37, 38] tetanus [39] and influenza [40, 41] vaccines compared to controls. One study showed a protective response to Haemophilus influenzae type b vaccine in most SLE patients studied, but it had no control group for comparison. [42] Vaccination did not appear to increase disease activity or the likelihood of a disease exacerbation in SLE patients. [41, 42]

Immunosuppressive medications may dampen the immune response to vaccination and the response may vary with the type of vaccine. Kapetanovic and colleagues [43, 44] conducted a study to evaluate the antibody response in RA patients to influenza and pneumococcal vaccine. RA patients treated with methotrexate without TNF alpha inhibitors produced a better antibody response to influenza vaccination compared to subjects treated with TNF alpha inhibitors alone or in combination with methotrexate and/or other disease-modifying anti-rheumatic drugs. [43] However, RA patients receiving TNF alpha inhibitors without 
methotrexate mounted a higher antibody response after pneumococcal vaccination compared to subjects receiving methotrexate (with or without TNF alpha inhibitors). [44]

\section{The evidence supporting current immunization guidelines in IBD patients is incomplete}

In 2004, a committee formed by the Crohn's and Colitis Foundation of America provided a consensus statement on immunizations in IBD patients. [45] The consensus paper reviewed the immunologic alterations in patients with IBD and routine immunization schedules (e.g., pneumococcal vaccination) and those for travel to high risk areas (e.g., yellow fever and typhoid). While the consensus statement reflected a recommendation by a well respected group of experts, the paper only identified a few formal vaccine studies performed in immunocompromised populations. They noted case reports of complications after measles virus vaccination, and a study in which patients with leukemia on long-term 6mercaptopurine therapy tolerated the varicella vaccine. At the time the authors wrote their guidelines, there was little published literature on immunizing transplant patients with live vaccines. [31, 32] Although the panel stated that most patients would benefit from immunization with these live vaccines without complications, the experts still recommended against the use of live vaccines in IBD patients on immunosuppressive therapy given the possibility of vaccine associated disease. The panel did recommend the use of inactivated vaccines (including pneumococcal and influenza vaccine) whether or not IBD patients were on immunosuppressive therapy. [45] The paucity of formal evidence in the 2004 IBD Immunization Guideline emphasizes the need for additional studies.

\section{Immunization studies in adults and children with inflammatory bowel disease}

\section{IBD patients are under-immunized}

Similar to pediatric patients with chronic illnesses, data have shown that IBD patients tend to be under-immunized. Melmed et al [46] conducted a study where IBD patients completed a questionnaire to assess their immunization history and exposure risk to influenza, pneumococcus, tetanus, varicella, and viral hepatitis. Serology to hepatitis A, hepatitis B, and varicella were evaluated in 41 of these subjects who voluntarily gave a blood sample. Of 169 patients who completed the questionnaires, $28 \%$ received regular influenza immunizations, $9 \%$ received a pneumococcal vaccination, and $45 \%$ received a tetanus vaccination within the past 10 years. Among reasons for not getting the influenza vaccine, patients cited they were unaware they needed it, afraid of adverse events, or believed the vaccine would not be efficacious.

Eleven percent of subjects in the study by Melmed and colleagues [46] were considered at risk for varicella because they did not have a history of varicella infection or vaccination. Of the patients who had varicella zoster virus antibody titers evaluated, $96 \%(24 / 25)$ of patients with a history of varicella infection or immunization were immune, compared to $25 \%(1 / 4)$ of those who had no history of infection or immunization. This finding emphasizes that a 
patient's history of varicella infection or immunization is a good predictor of immunity or lack thereof.

Melmed [46] also found that forty-four percent of patients in the study had at least one risk factor for hepatitis B (e.g., had a blood transfusion or tattoos). However, only $28 \%$ of all patients (47/169) had been vaccinated. Of this subgroup that was immunized, 33\% (3/9) had detectable hepatitis B surface antibody titers.

\section{Prior studies involving influenza vaccination in pediatric IBD patients}

Studies conducted in children with IBD have involved the influenza vaccine, and shown that it is generally immunogenic and safe in this patient population. Mamula et al [47] prospectively evaluated serologic responses to the 2002-2004 inactivated influenza vaccines in 51 pediatric IBD patients and 29 healthy children. The study demonstrated that children with IBD had a lower seroconversion rate to one of three influenza strains in the vaccine compared to healthy controls ( $89 \%$ versus $62 \%$ ). In addition, patients receiving both infliximab and immunomodulators were less likely to seroconvert two vaccine strains compared to healthy controls (63\% versus $95 \%$ for strain A/New Caledonia, 33\% versus $89 \%$ for strain B/Hong Kong). There were no serious adverse events related to the vaccine. Vaccination did not worsen clinical activity of IBD.

We [48] recently conducted a prospective, open label study to evaluate the safety and immunogenicity of inactivated influenza vaccine in 137 pediatric IBD patients during the 2007-2008 influenza season. The study suggested that the influenza vaccine was safe and immunogenic in children with IBD. The vaccine was well tolerated with few side effects. There were no serious vaccine-associated adverse events. Immunization did not have an effect on severity of disease activity. A high proportion of patients were seroprotected regardless of immunosuppression status, especially to A strains (79-100\% for A strains, $21-80 \%$ for B strain). However, in the subset of patients who were not seroprotected prior to vaccination, patients receiving anti-TNF therapy were less likely to be seroprotected against influenza strain B after vaccination (14\%) compared to patients on other types of IBD therapy $(32 \%-75 \%)$. [48]

In the same study [48], we also compared the proportion of patients who were seroprotected after vaccination to a cohort of pediatric historical healthy controls $(n=76)$ who were immunized with the same influenza strains as IBD patients in the study during the same influenza season (2007-2008). [49] The proportion of patients who were seroprotected against the two influenza A strains was high, and similar between historical controls (84-85\%) and IBD patients (79-100\%) in our study. However, the lower seroprotection rate for strain B in healthy controls suggested that this strain was less immunogenic in general $(57 \%)$. [49]

\section{Prior studies involving vaccination in adult IBD patients}

One early study by Stevens et al [50] showed that adults with IBD who received a booster immunization with tetanus and diphtheria toxoids produced inadequate levels of antibody titers after vaccination. Specifically, patients with CD and UC who were immunized with a tetanus toxoid booster had lower antibody levels in vitro and produced a suboptimal serum 
tetanus IgG response compared to controls with systemic lupus erythematosus or gastrointestinal disease. Many of the IBD patients who produced an inadequate IgG antibody response to tetanus also had a suboptimal IgG antibody response to diphtheria vaccination.

Other studies found that the immune response to vaccinations in IBD patients may depend on the type of immunosuppressive therapy they receive, especially if they receive anti-TNF therapy. For example, Gelinck and colleagues [51] studied the serologic response to influenza vaccine in 112 patients who were treated with TNF alpha inhibitor for autoimmune diseases, including 22 patients with IBD and 90 patients with rheumatologic disease. The percentage of subjects who had a seroprotective titer was high (80-94\%) and there was no difference among patients who were treated with TNF alpha inhibitor, patients who were treated with another immunosuppressive medication, and healthy controls. However, post-vaccination GMT against two strains was significantly lower in subjects treated with TNF alpha inhibitor compared to the other two groups. In addition, seroconversion rate to all three strains was lower in patients receiving TNF alpha inhibitor compared to patients not receiving TNF alpha inhibitor. No major side effects or worsening of underlying disease in patients were reported.

Another study by Melmed and colleagues [52] evaluated the immunogenicity to 23-valent pneumococcal polysaccharide vaccine in IBD patients receiving both anti-TNF and immunomodulator therapy, IBD patients not receiving any immunosuppressive therapy, and in healthy controls. IBD patients who received combination immunosuppressive therapy mounted a lower immune response compared to IBD patients who received nonimmunosuppressive therapy and to controls. These two latter groups exhibited a similar response.

\section{Summary}

In conclusion, there is a need for more data on the immune response to vaccinations in patients with IBD and other chronic illnesses. Research on patients with chronic illnesses or who are immunocompromised suggest there are varying degrees of antibody titers that develop after vaccinations. Population studies and questionnaires conducted on adult patients with IBD suggest this population may not be receiving routine vaccines, and may not be seroprotected against various vaccine-preventable infections. The currently available data suggest a good immune response to influenza vaccine, even if IBD patients are receiving systemic immunosuppression. However, some studies have suggested that patients on TNF alpha inhibitors may have a slightly decreased immune response; this subpopulation may benefit from booster shots, but formal studies of this strategy have not been published. Whichever therapy is used, there do not appear to be any significant adverse events from inactivated vaccines.

It is important to conduct further research to evaluate the immune response in IBD patients to various types of vaccines (such as meningitis and human papillomavirus vaccines). If there is evidence that patients do not form an adequate immune response after vaccination, then perhaps clinical guidelines should suggest booster doses. In addition, patients and 
physicians may falsely assume that these patients will form antibodies and be adequately protected long-term. This latter point argues for further research to examine the sustainability of titers. Even if patients initially form adequate antibody titers after vaccination, these titers may wane and leave patients unknowingly susceptible to infection.

Current guidelines suggest against immunizing IBD patients on immunosuppressive therapy with live vaccines such as varicella. [45] However, data from transplant patients suggest such immunization may be safe. In addition, the immunocompromised state of IBD patients on immunosuppression increases their risk of complications from wild type varicella, making it even more crucial that these patients be protected against varicella infection. Therefore, the efficacy and safety of varicella vaccine in patients receiving immunomodulators is a much needed area of research. In the meantime, for immunocompromised children who are at risk for repeated exposure to varicella in school or daycare, physicians should consider performing a varicella titer and being aware of their immune status.

\section{REFERENCES:}

1. Hugot JP, Chamaillard M, Zouali H, Lesage S, Cezard JP, Belaiche J, et al. Association of NOD2 leucine-rich repeat variants with susceptibility to Crohn's disease. Nature 2001;411(6837):599-603. [PubMed: 11385576]

2. Ogura Y, Bonen DK, Inohara N, Nicolae DL, Chen FF, Ramos R, et al. A frameshift mutation in NOD2 associated with susceptibility to Crohn's disease. Nature 2001;411(6837):603-6. [PubMed: 11385577]

3. Baldassano RN, Bradfield JP, Monos DS, Kim CE, Glessner JT, Casalunovo T, et al. Association of variants of the interleukin-23 receptor gene with susceptibility to pediatric Crohn's disease. Clin Gastroenterol Hepatol 2007;5(8):972-6. [PubMed: 17618837]

4. Duerr RH, Taylor KD, Brant SR, Rioux JD, Silverberg MS, Daly MJ, et al. A genome-wide association study identifies IL23R as an inflammatory bowel disease gene. Science 2006;314(5804): 1461-3. [PubMed: 17068223]

5. Danese S, Fiocchi C. Etiopathogenesis of inflammatory bowel diseases. World J Gastroenterol 2006;12(30):4807-12. [PubMed: 16937461]

6. Rufo PA, Bousvaros A. Current therapy of inflammatory bowel disease in children. Paediatr Drugs 2006;8(5):279-302. [PubMed: 17037946]

7. Aberra FN, Lichtenstein GR. Methods to avoid infections in patients with inflammatory bowel disease. Inflamm Bowel Dis 2005;11(7):685-95. [PubMed: 15973124]

8. Viget N, Vernier-Massouille G, Salmon-Ceron D, Yazdanpanah Y, Colombel JF. Opportunistic infections in patients with inflammatory bowel disease: prevention and diagnosis. Gut 2008;57(4): 549-58. [PubMed: 18178610]

9. Nguyen GC, Kaplan GG, Harris ML, Brant SR. A national survey of the prevalence and impact of Clostridium difficile infection among hospitalized inflammatory bowel disease patients. Am J Gastroenterol 2008;103(6):1443-50. [PubMed: 18513271]

10. Kishore J, Ghoshal U, Ghoshal UC, Krishnani N, Kumar S, Singh M, et al. Infection with cytomegalovirus in patients with inflammatory bowel disease: prevalence, clinical significance and outcome. J Med Microbiol 2004;53(Pt 11):1155-60. [PubMed: 15496396]

11. Bhatia J, Bratcher J, Korelitz B, Vakher K, Mannor S, Shevchuk M, et al. Abnormalities of uterine cervix in women with inflammatory bowel disease. World J Gastroenterol 2006;12(38):6167-71. [PubMed: 17036389]

12. Kane S, Khatibi B, Reddy D. Higher incidence of abnormal Pap smears in women with inflammatory bowel disease. Am J Gastroenterol 2008;103(3):631-6. [PubMed: 17941962] 
13. Papadakis KA, Tung JK, Binder SW, Kam LY, Abreu MT, Targan SR, et al. Outcome of cytomegalovirus infections in patients with inflammatory bowel disease. Am J Gastroenterol 2001;96(7):2137-42. [PubMed: 11467645]

14. Posthuma EF, Westendorp RG, van der Sluys Veer A, Kluin-Nelemans JC, Kluin PM, Lamers CB. Fatal infectious mononucleosis: a severe complication in the treatment of Crohn's disease with azathioprine. Gut 1995;36(2):311-3. [PubMed: 7883236]

15. Francois-Dufresne A, Garbino J, Ricou B, Wunderli W. ARDS caused by herpes simplex virus pneumonia in a patient with Crohn's disease: a case report. Intensive Care Med 1997;23(3):345-7. [PubMed: 9083240]

16. Deutsch DE, Olson AD, Kraker S, Dickinson CJ. Overwhelming varicella pneumonia in a patient with Crohn's disease treated with 6-mercaptopurine. J Pediatr Gastroenterol Nutr 1995;20(3):3513. [PubMed: 7608833]

17. Korelitz BI, Fuller SR, Warman JI, Goldberg MD. Shingles during the course of treatment with 6mercaptopurine for inflammatory bowel disease. Am J Gastroenterol 1999;94(2):424-6. [PubMed: 10022640]

18. Keane J, Gershon S, Wise RP, Mirabile-Levens E, Kasznica J, Schwieterman WD, et al. Tuberculosis associated with infliximab, a tumor necrosis factor alpha-neutralizing agent. N Engl J Med 2001;345(15):1098-104. [PubMed: 11596589]

19. Galandiuk S, Davis BR. Infliximab-induced disseminated histoplasmosis in a patient with Crohn's disease. Nat Clin Pract Gastroenterol Hepatol 2008;5(5):283-7. [PubMed: 18398409]

20. Jain VV, Evans T, Peterson MW. Reactivation histoplasmosis after treatment with anti-tumor necrosis factor alpha in a patient from a nonendemic area. Respir Med 2006;100(7):1291-3. [PubMed: 16545951]

21. Itaba S, Iwasa T, Sadamoto Y, Nasu T, Misawa T, Inoue K, et al. Pneumocystis pneumonia during combined therapy of infliximab, corticosteroid, and azathioprine in a patient with Crohn's disease. Dig Dis Sci 2007;52(6):1438-41. [PubMed: 17404870]

22. Kaur N, Mahl TC. Pneumocystis jiroveci (carinii) pneumonia after infliximab therapy: a review of 84 cases. Dig Dis Sci 2007;52(6):1481-4. [PubMed: 17429728]

23. Zignol M, Peracchi M, Tridello G, Pillon M, Fregonese F, D’Elia R, et al. Assessment of humoral immunity to poliomyelitis, tetanus, hepatitis B, measles, rubella, and mumps in children after chemotherapy. Cancer 2004;101(3):635-41. [PubMed: 15274078]

24. Chaves TS, Pereira LM, De Santos SS, David-Neto E, Lopes MH. Evaluation of the vaccination status in pediatric renal transplant recipients. Pediatr Transplant 2008;12(4):432-5. [PubMed: 18466429]

25. Nachman S, Kim S, King J, Abrams EJ, Margolis D, Petru A, et al. Safety and immunogenicity of a heptavalent pneumococcal conjugate vaccine in infants with human immunodeficiency virus type 1 infection. Pediatrics 2003;112(1 Pt 1):66-73. [PubMed: 12837869]

26. Rutstein RM, Rudy BJ, Cnaan A. Response of human immunodeficiency virus-exposed and infected infants to Haemophilus influenzae type b conjugate vaccine. Arch Pediatr Adolesc Med 1996;150(8):838-41. [PubMed: 8704891]

27. Matsuzaki A, Suminoe A, Koga Y, Kinukawa N, Kusuhara K, Hara T. Immune response after influenza vaccination in children with cancer. Pediatr Blood Cancer 2005;45(6):831-7. [PubMed: 16007602]

28. Brydak LB, Roszkowska-Blaim M, Machala M, Leszczynska B, Sieniawska M. Antibody response to influenza immunization in two consecutive epidemic seasons in patients with renal diseases. Vaccine 2000;18(28):3280-6. [PubMed: 10869773]

29. Drachman R, Isacsohn M, Rudensky B, Drukker A. Vaccination against hepatitis B in children and adolescent patients on dialysis. Nephrol Dial Transplant 1989;4(5):372-4. [PubMed: 2528085]

30. Pillion G, Chiesa M, Maisin A, Schlegel N, Loirat C. Immunogenicity of hepatitis B vaccine (HEVAC B) in children with advanced renal failure. Pediatr Nephrol 1990;4(6):627-9. [PubMed: 2088465]

31. Kano H, Mizuta K, Sakakihara Y, Kato H, Miki Y, Shibuya N, et al. Efficacy and safety of immunization for pre- and post- liver transplant children. Transplantation 2002;74(4):543-50. [PubMed: 12352917] 
32. Weinberg A, Horslen SP, Kaufman SS, Jesser R, Devoll-Zabrocki A, Fleckten BL, et al. Safety and immunogenicity of varicella-zoster virus vaccine in pediatric liver and intestine transplant recipients. Am J Transplant 2006;6(3):565-8. [PubMed: 16468967]

33. Schulman SL, Deforest A, Kaiser BA, Polinsky MS, Baluarte HJ. Response to measles-mumpsrubella vaccine in children on dialysis. Pediatr Nephrol 1992;6(2):187-9. [PubMed: 1571219]

34. Chalmers A, Scheifele D, Patterson C, Williams D, Weber J, Shuckett R, et al. Immunization of patients with rheumatoid arthritis against influenza: a study of vaccine safety and immunogenicity. J Rheumatol 1994;21(7):1203-6. [PubMed: 7966058]

35. Kubota T, Nii T, Nanki T, Kohsaka H, Harigai M, Komano Y, et al. Anti-tumor necrosis factor therapy does not diminish the immune response to influenza vaccine in Japanese patients with rheumatoid arthritis. Mod Rheumatol 2007;17(6):531-3. [PubMed: 18084712]

36. Fomin I, Caspi D, Levy V, Varsano N, Shalev Y, Paran D, et al. Vaccination against influenza in rheumatoid arthritis: the effect of disease modifying drugs, including TNF alpha blockers. Ann Rheum Dis 2006;65(2):191-4. [PubMed: 16014674]

37. Elkayam O, Ablin J, Caspi D. Safety and efficacy of vaccination against streptococcus pneumonia in patients with rheumatic diseases. Autoimmun Rev 2007;6(5):312-4. [PubMed: 17412304]

38. Jarrett MP, Schiffman G, Barland P, Grayzel AI. Impaired response to pneumococcal vaccine in systemic lupus erythematosus. Arthritis Rheum 1980;23(11):1287-93. [PubMed: 7447963]

39. Nies K, Boyer R, Stevens R, Louie J. Anti-tetanus toxoid antibody synthesis after booster immunization in systemic lupus erythematosus. Comparison of the in vitro and in vivo responses. Arthritis Rheum 1980;23(12):1343-50. [PubMed: 7006611]

40. Abu-Shakra M, Press J, Varsano N, Levy V, Mendelson E, Sukenik S, et al. Specific antibody response after influenza immunization in systemic lupus erythematosus. J Rheumatol 2002;29(12): 2555-7. [PubMed: 12465151]

41. Williams GW, Steinberg AD, Reinertsen JL, Klassen LW, Decker JL, Dolin R. Influenza immunization in systemic lupus eruthematosus. A double-blind trial. Ann Intern Med 1978;88(6): 729-34. [PubMed: 352210]

42. Battafarano DF, Battafarano NJ, Larsen L, Dyer PD, Older SA, Muehlbauer S, et al. Antigenspecific antibody responses in lupus patients following immunization. Arthritis Rheum 1998;41(10):1828-34. [PubMed: 9778224]

43. Kapetanovic MC, Saxne T, Nilsson JA, Geborek P. Influenza vaccination as model for testing immune modulation induced by anti-TNF and methotrexate therapy in rheumatoid arthritis patients. Rheumatology (Oxford) 2007;46(4):608-11. [PubMed: 17114801]

44. Kapetanovic MC, Saxne T, Sjoholm A, Truedsson L, Jonsson G, Geborek P. Influence of methotrexate, TNF blockers and prednisolone on antibody responses to pneumococcal polysaccharide vaccine in patients with rheumatoid arthritis. Rheumatology (Oxford) 2006;45(1): 106-11. [PubMed: 16287919]

45. Sands BE, Cuffari C, Katz J, Kugathasan S, Onken J, Vitek C, et al. Guidelines for immunizations in patients with inflammatory bowel disease. Inflamm Bowel Dis 2004;10(5):677-92. [PubMed: 15472534]

46. Melmed GY, Ippoliti AF, Papadakis KA, Tran TT, Birt JL, Lee SK, et al. Patients with inflammatory bowel disease are at risk for vaccine-preventable illnesses. Am J Gastroenterol 2006;101(8):1834-40. [PubMed: 16817843]

47. Mamula P, Markowitz JE, Piccoli DA, Klimov A, Cohen L, Baldassano RN. Immune response to influenza vaccine in pediatric patients with inflammatory bowel disease. Clin Gastroenterol Hepatol 2007;5(7):851-6. [PubMed: 17544875]

48. Lu Y, Jacobson DL, Ashworth LA, Grand RJ, Meyer AL, McNeal MM, et al. Immune response to influenza vaccine in children with inflammatory bowel disease. Am J Gastroenterol 2009;104(2): 444-53. [PubMed: 19174786]

49. Ye Z Influenza vaccine responses. http://www.fda.gov/ohrms/dockets/ac/08/slides/ 2008-4348S2-5_files/frame.htm 2008.

50. Stevens R, Oliver M, Brogan M, Heiserodt J, Targan S. Defective generation of tetanus-specific antibody-producing B cells after in vivo immunization of Crohn's disease and ulcerative colitis patients. Gastroenterology 1985;88(6):1860-6. [PubMed: 3873371] 
51. Gelinck LB, van der Bijl AE, Beyer WE, Visser LG, Huizinga TW, van Hogezand RA, et al. The effect of anti-tumour necrosis factor alpha treatment on the antibody response to influenza vaccination. Ann Rheum Dis 2008;67(5):713-6. [PubMed: 17965123]

52. Melmed G TNF blockers and immunomodulators impair antibody responses to pneumococcal polysaccharide vaccine in patients with inflammatory bowel disease. Gastroenterology 2008;134(4): Abstract S1 A68.

53. Cytomegalovirus Infection. Red Book: 2006 Report of the Committee on Infectious Diseases. In: Pickering L, Baker CJ, Long SS, McMillan JA, editor. 27th ed. Elk Grove Village, IL: American Academy of Pediatrics; 2006 p. 273-277

54. Epstein-Barr Virus Infections. Red Book: 2006 Report of the Committee on Infectious Diseases. In: Pickering L, Baker CJ, Long SS, McMillan JA, editor. 27th ed. Elk Grove Village, IL: American Academy of Pediatrics; 2006 p. 286-288.

55. CDC. Epstein-Barr Virus and Infectious Mononucleosis In: http://www.cdc.gov/ncidod/diseases/ ebv.htm; 2008.

56. Hepatitis B Red Book: 2006 Report of the Committee on Infectious Diseases. In: Pickering L, Baker CJ, Long SS, McMillan JA, editor. 27th ed. Elk Grove Village, IL: American Academy of Pediatrics; 2006 p. 335-355.

57. Herpes simplex. Red Book: 2006 Report of the Committee on Infectious Diseases. In: Pickering L, Baker CJ, Long SS, McMillan JA, editor. 27th ed. Elk Grove Village, IL: American Academy of Pediatrics; 2006 p. 361-371.

58. Influenza. Red Book: 2006 Report of the Committee on Infectious Diseases. In: Pickering L, Baker CJ, Long SS, McMillan JA, editor. 27th ed. Elk Grove Village, IL: American Academy of Pediatrics; 2006 p. 401-411.

59. CDC. Influenza Antiviral Medications: Summary for Clinicians In: http://www.cdc.gov/flu/ professionals/antivirals/summary-clinicians.htm; 2008.

60. Varicella-Zoster Infections. Red Book: 2006 Report of the Committee on Infectious Diseases. In: Pickering L, Baker CJ, Long SS, McMillan JA, editor. 27th ed. Elk Grove Village, IL: American Academy of Pediatrics; 2006 p. 711-725.

61. Human Papillomaviruses. Red Book: 2006 Report of the Committee on Infectious Diseases. In: Pickering L, Baker CJ, Long SS, McMillan JA, editor. 27th ed. Elk Grove Village, IL: American Academy of Pediatrics; 2006 p. 473-477.

62. CDC. Human Papillomavirus (HPV) Infection. In: http://www.cdc.gov/STD/HPV; 2008.

63. Clostridium difficile. Red Book: 2006 Report of the Committee on Infectious Diseases. In: Pickering L, Baker CJ, Long SS, McMillan JA, editor. 27th ed. Elk Grove Village, IL: American Academy of Pediatrics; 2006 p. 261-263.

64. Tuberculosis. Red Book: 2006 Report of the Committee on Infectious Diseases. In: Pickering L, Baker CJ, Long SS, McMillan JA, editor. 27th ed. Elk Grove Village, IL: American Academy of Pediatrics; 2006 p. 678-698.

65. Histoplasmosis. Red Book: 2006 Report of the Committee on Infectious Diseases. In: Pickering L, Baker CJ, Long SS, McMillan JA, editor. 27th ed. Elk Grove Village, IL: American Academy of Pediatrics; 2006 p. 371-374.

66. Pneumocystis jiroveci Infections. Red Book: 2006 Report of the Committee on Infectious Diseases. In: Pickering L, Baker CJ, Long SS, McMillan JA, editor. 27th ed. Elk Grove Village, IL: American Academy of Pediatrics; 2006 p. 537-542. 
Table 1.

Common opportunistic infections in IBD patients.

\begin{tabular}{|c|c|c|c|}
\hline Infection & Reference & Preventative mechanism & Screening test \\
\hline \multicolumn{4}{|l|}{ Viral } \\
\hline cytomegalovirus & {$[7,8,10,13,53]$} & handwashing & $\begin{array}{l}\text { serology (CMV antigenemia, culture, } \\
\text { CMV DNA by PCR, biopsy) }\end{array}$ \\
\hline Epstein-Barr virus & {$[7,8,14,54,55]$} & avoid exposure & serology, monospot (culture, PCR) \\
\hline hepatitis B & {$[8,56]$} & vaccine, hepatits B immune globulin & $\begin{array}{l}\text { HBsAg (HBeAg, anti-HBs, anti-HBc, } \\
\text { anti-HBe, HBV DNA/PCR) }\end{array}$ \\
\hline herpes simplex & {$[7,8,15,57]$} & avoid exposure & culture, serology, ?biopsy \\
\hline influenza & {$[8,58,59]$} & vaccine, oseltamivir, zanamivir, ?amantadine & $\begin{array}{l}\text { serology (viral culture, rapid antigen } \\
\text { testing, PCR, immunofluorescence } \\
\text { assays) }\end{array}$ \\
\hline varicella & {$[7,8,16,17,60]$} & vaccine zoster immune globulin & $\begin{array}{c}\text { serology (Tzanck smear, ?viral culture, } \\
\text { PCR, direct fluorescence antibody, } \\
\text { biopsy) }\end{array}$ \\
\hline human papillomavirus & {$[7,8,11,12,61$} & vaccine, sexual abstinence, barrier contraception & $\begin{array}{l}\text { serology, (Pap smear, pelvic exam, } \\
\text { HPV DNA test) }\end{array}$ \\
\hline \multicolumn{4}{|l|}{ Bacterial } \\
\hline Clostridium difficile & {$[7-9,63]$} & $\begin{array}{l}\text { gown and gloves, soap and handwashing, properly } \\
\text { handling of contaminated waste, disinfect fomites, } \\
\text { limit antibiotic use }\end{array}$ & $\begin{array}{l}\text { stool test (toxin A and B) (lower } \\
\text { endoscopy) }\end{array}$ \\
\hline tuberculosis & {$[7,8,18,64]$} & isoniazid & $\begin{array}{c}\text { PPD, chest x-ray, (Mycobacterium } \\
\text { tuberculosis culture, acid-fast bacillus } \\
\text { smear, biopsy) }\end{array}$ \\
\hline \multicolumn{4}{|l|}{ Fungal } \\
\hline histoplasmosis & {$[7,8,19,20,65]$} & avoid exposure to contaminated soil and dust & $\begin{array}{l}\text { serology, CXR (culture, stains, titers, } \\
\text { H. capsulatum polysaccharide antigen, } \\
\text { lung biopsy) }\end{array}$ \\
\hline $\begin{array}{l}\text { Pneumocystis jiroveci } \\
\text { (carinii) pneumonia }\end{array}$ & {$[7,8,21,22,66]$} & trimethoprim/sulfamethoxazole, atovaquone & $\begin{array}{l}\text { chest X-ray (lung biopsy, staining of } \\
\text { respiratory tract secretions) }\end{array}$ \\
\hline
\end{tabular}

